\title{
A PERSPECTIVA DE EDUCAÇÃO POPULAR DE PAULO FREIRE E O TRABALHO DA PEDAGOGA: UM DIÁLOGO POSSÍVEL
}

\author{
Grazielle Kusma Baisan Fernandes ${ }^{1}$ \\ Marcus Quintanilha da Silva²
}

\section{RESUMO}

A presente pesquisa tem como objetivo estabelecer um diálogo sobre possibilidades do embasamento das atribuições da pedagoga na organização do trabalho pedagógico a partir de alguns pressupostos da educação popular freiriana. Partindo de uma revisão literária, buscou-se retomar as principais conceituações da educação popular freiriana, compreender as funções essenciais do pedagogo na organização pedagógica e promover um diálogo entre as possibilidades de o trabalho pedagógico ser pautado na perspectiva da educação popular. Os resultados evidenciaram que é possível o diálogo entre a metodologia de Freire e a organização pedagógica, através da proposição, por parte da pedagoga, de instrumentos para a transformação social, de sua atuação na construção do projeto político pedagógico, da formação continuada, de atividades de gestão, administrativas e pedagógicas, da condução do processo de avaliação, tendo como base o diálogo, a participação comunitária, valorização dos saberes prévios e do contexto no qual a escola se insere, desenvolvimento do olhar crítico e a práxis como um elemento norteador de seu trabalho e dos demais profissionais da instituição.

Palavras-chave: Paulo Freire. Educação Popular. Escola Cidadã. Trabalho Pedagógico.

\section{ABSTRACT}

The present research aims to bring a dialogue about possibilities of groun-

'Licenciada em Pedagogia - Faculdade Unina. Pós-graduanda em MBA - Gestão Estratégica de Pessoas - Faculdade Descomplica. E-mail: gkusma@gmail.com

${ }^{2}$ Doutor em Educação - UFPR. Professor do Magistério Superior - Faculdade Unina. E-mail: marcusquintanlha@hotmail.com 
ding the pedagogue's attributions in the organization of the pedagogical work from some assumptions of Freire's popular education. Starting from a literary review, we sought to retake the main concepts of freirian popular education, understand the main functions of the pedagogue in the pedagogical organization and establish a dialogue between the possibilities of pedagogical work being based on the perspective of popular education. The results showed that the dialogue between Freire's methodology and the pedagogical organization is possible, through the pedagogue's proposition of instruments for social transformation, its role in the construction of the pedagogical political project, continuing education, management activities, administrative and pedagogical, conducting the evaluation process, based on dialogue, community participation, valuing prior knowledge and the context in which the school is inserted, developing a critical view and praxis as a guiding element of its work and of the other professionals of the institution.

Keywords: Paulo Freire. Popular Education. Citizen School. Pedagogical Work.

\section{INTRODUÇÃO}

Historicamente, a estrutura capitalista de educação tem como fundamento reproduzir a ideologia do capital, através da alienação e das dominações das classes (CANDAU; OLIVEIRA, 2010). A concepção de educação popular surgiu como uma contraproposta a esse ideal de educação, com o intuito de trazer consciência às classes populares, para que conseguissem se libertar de tais dominações. Um dos seus precursores foi Paulo Freire, a partir de sua experiência com a Educação de Jovens e Adultos (FREIRE, 2005).

Todavia, mesmo com a Educação de Jovens e adultos sendo o ponto de partida, entende-se que seus pressupostos possam servir de reflexão e base para ação em outras modalidades/etapas de ensino e, especificamente no foco de interesse deste trabalho, pautando o trabalho da pedagoga. Nesse sentido, este estudo tem como objetivo promover um diálogo sobre possibilidades do embasamento do trabalho da pedagoga na organização do trabalho pedagógico a partir de alguns pressupostos da educação popular freiriana.

Em relação à metodologia de pesquisa, este estudo se encaixa em uma revisão de literatura, definida por Cordeiro et al. (2007) como um processo de busca, descrição e análise de um campo do conhecimento em que o objetivo 
é responder a uma pergunta ou refletir sobre um tema. No entanto, esta revisão de literatura não consistiu em um trabalho de esgotamento de fontes a respeito do tema, mas uma seleção crítica e opinativa de trabalhos contidos em artigos de periódicos, capítulos de livros e livros em sua completude, que pudessem compor o aporte teórico do estudo.

As intenções da pesquisa eram abordar inicialmente os conceitos e objetivos da educação popular. Posteriormente, buscou-se elucidar as incumbências da pedagoga, relacionando-as com as conceituações da educação popular para, nessa perspectiva, entender a pedagoga como profissional que pode compreender a educação como sendo o fazer social e político.

\section{EDUCAÇÃO POPULAR EM PAULO FREIRE}

A sociedade brasileira é reflexo de uma educação colonial que tinha como princípio a hegemonia política, estabelecendo um padrão étnico, econômico e cultural baseado nos colonizadores, isto é, os europeus. Dentro dessa imposição cultural, o que não se adequava aos padrões, passava a ser considerado "errado", o que Oliveira e Candau (2010) denominam de fetichismo epistêmico, em que a cultura e as ideias dos colonialistas se tornaram sedutoras e passíveis de imitação.

Nessa perspectiva, Paulo Freire (1979) considera o Brasil uma sociedade fechada, isto é, uma sociedade dependente de outros países, cultural e politicamente falando. É uma sociedade que não tem identidade própria e vive na orla dos países colonizadores. Por essa razão, não existe uma luta pela concessão de direitos, pois, dentro de uma sociedade fechada, as pessoas não compreendem a necessidade de serem autônomas e responsáveis por suas decisões, naturalizando o conformismo.

Nesse contexto, as primeiras discussões sobre educação popular surgiram no Brasil no início do século 20 como uma forma de manifesto das políticas educacionais da época, marcadas pelas dinâmicas neoliberais, que reiteravam a desigualdade social, fortalecida pelas classes dominantes. Dessa forma, a educação popular assumiu a tarefa, a partir de movimentos sociais, de trazer consciência política para uma parcela marginalizada pela sociedade, criando 
sua própria leitura de mundo.

A industrialização e o êxodo rural foram fatores motivadores da criação de programas de Educação de Jovens e Adultos no Brasil. Nesse contexto, o veto do direito ao voto dos analfabetos influenciou diretamente o processo de alfabetização no país, visto que a classe dominante utilizava os programas de alfabetização como moeda de troca com as classes populares, que, quando alfabetizadas, sentiam-se gratas, assumindo a responsabilidade por manter os mesmos governantes no poder. Além disso, a educação nesse momento também serviu para dar qualificação técnica para a classe popular (BRANDÃO, 1984).

Em concordância com Brandão (1984), a educação, do ponto de vista capitalista, é sempre definida como uma forma de manter a ordem social sem contestação, por parte das classes dominantes que necessitam de uma mão de obra que tenha a força de trabalho do proletariado. As classes dominantes costumam ter como aliada a falsa percepção de generosidade, trazendo a ideia de que todas as suas conquistas são fruto de seus méritos e que, se o oprimido não conquistou, é porque não foi capaz (FREIRE, 2014).

Assim como a educação disponibilizada pelas classes que detêm o poder político, a educação popular também tem caráter ideológico. De acordo com Freire (2008), não existe possibilidade de uma educação neutra, que ministre ideias genéricas; de forma geral a educação é um ato político. Na perspectiva do autor, tem-se, de um lado, uma educação libertadora e, de outro, um viés conservador e dominador pelas classes dominantes.

Paulo Freire aponta que a situação de hospedagem ocorre quando o oprimido tem dentro de si o opressor, ou seja, devido a circunstâncias históricas, o oprimido carrega consigo a ideia de que a dominação é a metodologia adequada em qualquer processo existente. Isso torna o processo de libertação mais dificultoso, pois o oprimido não se identifica como tal e reproduz as ações das classes dominantes. Dentro dessa relação opressor-oprimido, não basta o oprimido sair da situação de opressão, como sustentado por Freire (2014); é necessário ele identificar e criticar essa relação, pois, quando o oprimido sem consciência deixa esse papel, ele automaticamente assume o papel de 
opressor, criando assim um ciclo vicioso. Para que seja possível essa relação de autoidentificação, são imprescindíveis práticas educativas que visem à conscientização política e, principalmente, tratar o educando como sujeito de sua história.

Na educação tradicional, ministrada pelas classes dominantes, os educadores têm como metodologia o ensino bancário que, de acordo com Freire (2014), caracteriza-se por uma metodologia na qual se deposita o conteúdo desejado - em sua maioria, sobre a cultura da classe dominante - e se espera que o educando saque esse conteúdo e devolva para o educador da mesma forma que o recebeu. Esse método trata o educando como uma tábula rasa e o educador como detentor do conhecimento. Inibe o educando a criar, refletir, problematizar e trabalhar sua criticidade, pois nesse ensino não há sujeitos, criando assim a cultura do silêncio, que, segundo Freire (1979), instala-se quando o educando não demonstra mais interesse em contar sua história e cultura e vira um reprodutor, seguindo as ideias de quem lhe impõe a voz.

A práxis pedagógica da educação popular é totalmente comprometida com os oprimidos, tendo como objetivo libertar esses sujeitos das correntes da opressão. Entende-se por práxis o processo dialógico entre a teoria e a prática, quando se concretiza a teoria. Para Freire (2014), práxis é quando de fato homens e mulheres refletem sobre a sociedade e, a partir desse momento, desenvolvem ações para transformá-la, sendo fundamental na prática de libertação.

Não existe práxis sem diálogo, o qual fundamenta a metodologia da educação popular. Com base em Freire, "[...] o diálogo é uma exigência existencial" (2014, p. 109), pois é um elemento indispensável para se conviver em sociedade. Se fundamentando na educação popular, o diálogo deve ser crítico e libertador, tendo como propósito dar voz aos que anteriormente tiveram esse direito negado.

Com base nessa perspectiva e contrário ao ensino bancário, foi criado o círculo de cultura, um espaço educativo em que educadores e educandos estabelecem relações e aprendizagens a partir do diálogo e das vivências. A metodologia que estrutura o círculo de cultura é o tema gerador, que tem como 
embasamento a valorização de saberes, não distinguindo as pessoas em sábias e ignorantes, mas evidenciando que todo saber é válido. Fundamenta-se em causar inquietude nos participantes, provocar o debate e estimular a curiosidade. Para Freire (2005), é nesses espaços que o povo consegue discutir os seus problemas e encontrar soluções, pois é a partir dessa dinâmica que ações concretas são estabelecidas.

No que tange ao conceito de transformação, é necessário compreender a importância da conscientização das classes populares, pois só assim será possível obter o resultado desejado. Mesmo que a educação popular tenha como foco a conscientização dos oprimidos, deve-se lembrar que o educador não conscientiza ninguém, a educação ocorre em conjunto com o educando. Como afirma Paulo Freire (2002), educando e educador são sujeitos desse processo, o ato de educar não é o ato de transmitir, mas sim criar condições de aprendizagem, tanto do educando quanto do educador. Todo conhecimento é válido, o educador aprende tanto quanto o educando.

Todo ser humano possui consciência, contudo, para Freire (1979), a conscientização vai muito além disso. Ser consciente é estar apto a estabelecer relações entre os fatos, fazendo uma leitura profunda do contexto sócio-histórico em que se está inserido. Para que haja a conscientização, é preciso que a cultura dominante seja desmitificada, pois é a partir desses mitos que os opressores mantêm o controle sobre as classes populares. Entretanto, quando desmitificadas, as classes dominantes reagem de forma negativa. Por essa razão, no processo de libertação, é importante que o oprimido tenha convicção e, mais do que isso, uma postura firme que não lhe permita voltar às correntes da opressão.

Freire (1979) chama esse processo de transição, que ocorre quando as contradições ficam explícitas, causando discrepância entre as classes, quando as massas percebem que também são dignas de ter acesso às artes, que as suas expressões são válidas e que não concordam com o sistema que lhes é imposto. De outro lado, as classes dominantes se recusam a ficar em situação de igualdade. É nesse momento que a consciência transitiva crítica passa a predominar na sociedade. E é contra esse processo que as classes dominantes lutam, pois, quando a sociedade se torna aberta, dificilmente os oprimidos que 
nela se encontram voltam a acreditar na falácia difundida por elas.

Posto isso, Freire (2014), ao fundamentar a educação popular, explica que ela deve mobilizar e engajar a comunidade a fim de viabilizar a capacidade de criticar a organização da sociedade, compreender a intenção política encontrada na realidade opressora, construir objetivos para transformar a realidade e ampliar a participação efetiva de todos.

Para Antunes e Padilha (2010), a escola cidadã, uma espécie de formatação pedagógica da educação popular freiriana, é identificada como uma escola que busca a emancipação dos que estão ali, instiga a aspiração pela mudança, deseja que a educação se torne um ato prazeroso, baseado na alegria, solidariedade, responsabilidade e afetividade, tendo como objetivo a transformação social e a formação plena dos indivíduos. As estratégias para a efetividade desse modelo de escola são diversas, mas a integração da educação, cultura, comunidade e escola, a gestão democrática, a avaliação (inclusive a institucional) e a inter/transdisciplinaridade do currículo são fundamentais.

\section{O TRABALHO DA PEDAGOGA NA ORGANIZAÇÃO DO TRABALHO PEDAGÓ- GICO E O DIÁLOGO COM A PERSPECTIVA FREIRIANA}

Entende-se que a pedagoga tem funções dentro e fora de sala de aula, pois ela participa de todos os processos educativos. Para Libâneo (2012), trata-se de uma profissional que atua em várias instâncias ligadas ao processo de ensino e aprendizagem, sendo caracterizada também como uma professora. Saviani (2012) corrobora com isso, salientando seu papel de organizar o trabaIho docente, mas reiterando que a imprevisibilidade da rotina escolar ou, nos termos do autor, acidentes de estrutura, também fazem parte do seu cotidiano. Ainda em concordância com o autor, essa profissional de educação é vista como o ponto de partida para consciência transitiva crítica, mesmo que não ministre as aulas, pois cabe a ela a parte técnica e política da ação pedagógica.

Para a proposta reflexiva deste trabalho, a delimitação das principais funções desenvolvidas no trabalho da pedagoga se baseou em Libâneo (2012) e sua categorização da organização do trabalho pedagógico a partir de seis 
campos: a) o planejamento e o projeto pedagógico-curricular; b) a organização e o desenvolvimento do currículo; c) a organização e o desenvolvimento do ensino; d) as práticas de gestão técnico-administrativas e pedagógico-curriculares; e) o desenvolvimento profissional; f) a avaliação institucional e da aprendizagem. Entretanto, é preciso ratificar que os seis campos, apesar de categorizados separadamente, podem estabelecer uma relação transversal. Exemplificando esse contexto, não há como conceber um Projeto Político Pedagógico - PPP - sem considerar todas as outras questões em sua construção e ressignificação.

No primeiro ponto a ser observado, a valorização dos saberes prévios em consonância com a valorização do saber científico, entende-se que é fazer com que todos os saberes se façam necessários e trabalhem em concordância, um apoiando o outro. Nessa perspectiva, é preciso compreender que as práticas pedagógicas curriculares são instrumentos da pedagoga, que servem como meio para atingir os objetivos da escola e que o PPP é o que norteia esses objetivos. Então, cabe à pedagoga certificar-se de que o currículo escolar promova o saber científico e considere também os saberes prévios dos educandos.

Portanto, é necessário construir com o professor um trabalho efetivo em sala de aula, ficando ao encargo da pedagoga viabilizar a formação continuada, que tem como princípio a reflexão sobre a docência, para que os educadores possam analisar seus conhecimentos e suas experiências, funcionando como uma orientação dos docentes. É nesses espaços que a pedagoga deve tratar com os professores a importância de determinar uma relação visceral entre o conhecimento informal e o formal, bem como a consideração disso no plano curricular abordado pela escola.

O diálogo, a participação comunitária e a formação cidadã orientam as práticas de uma instituição articulada com os interesses populares. É incumbência da pedagoga garantir que existam, dentro da escola, ações coletivas que viabilizem o diálogo, para ser possível significar a atuação dessa profissional em todo o âmbito educativo. As ferramentas pedagógicas utilizadas pela pedagoga para viabilizar o acesso democrático, que se faz essencial nesse processo, são os colegiados escolares, os grêmios estudantis, a associação de pais e 
mestres, os conselhos de escola, as assembleias e as reuniões na escola. Dentro dessas dinâmicas, é possível dialogar com a comunidade para compreender o que ela entende por educação e se o PPP está sendo satisfatório e atendendo a todos os segmentos escolares.

Outra questão essencial é corporificar um currículo que contenha as vivências, as necessidades e os anseios de todos os segmentos, visando à melhoria das ações e às garantias de aprendizagem, para tornar a escola um espaço gerador da consciência da necessidade de desenvolvimento das práticas que tenham como objetivo melhorar a vida da comunidade. É competência da escola viabilizar a cidadania aos educandos, cabendo à pedagoga criar possibilidades para que isso ocorra, através da construção de um currículo que traga a consciência política a eles.

É necessário vislumbrar a educação como um processo que ultrapassa a sala de aula, sendo capaz de transformar a sociedade. Para isso, a pedagoga é responsável pela adoção de medidas, a partir de ações coletivas, que desenvolvam o olhar crítico. É fundamental ter claro que esse desenvolvimento diz respeito a todos os segmentos escolares, inclusive os docentes. Pois, para desenvolver o olhar crítico nos educandos, é primordial que o professor já tenha esse olhar, porque não existe a possibilidade de levar alguém à criticidade, se não tem essa característica em si próprio.

Nesse sentido, é reponsabilidade da pedagoga a mediação entre a organização escolar e o trabalho docente, sendo necessário incorporar a conscientização nos professores, por meio do diálogo e das formações continuadas. Assim sendo, os educadores poderão repensar, de forma crítica, as suas ações, com o intuito de atualizar e aprimorar suas práxis, ou seja, a reflexão pós-ação, identificando as suas capacidades e as suas limitações.

Para tratar do contato com a comunidade, é necessário primeiramente valorizar o contexto em que a escola está inserida, pois não existe a possibilidade de estruturar uma dinâmica onde a pedagoga não conheça a realidade dos indivíduos com que ela irá trabalhar. Quando se fala em valorizar, está se falando de levar em consideração o contexto, pois, para a criação de ações efetivas, é fundamental ter em mente que não existe um padrão de organização, o que indica que cada contexto social exige uma atuação diferente. 
Como forma de organizar uma síntese deste diálogo, o quadro a seguir propõe uma sistematização deste breve ensaio, em consonância com os pressupostos da educação popular e características do trabalho da pedagoga, objetos de revisão teórica abordados neste trabalho. Ressalta-se que, em nenhum momento, este estudo pretendeu apresentar uma nova forma de orientação do trabalho da pedagoga na organização do trabalho pedagógico com base na perspectiva freiriana. A intenção é propor uma forma sistematizada de retomar o diálogo entre as dimensões teórica (educação em Paulo Freire) e organizacional/prática (trabalho da pedagoga).

Quadro 1 - Possibilidades de orientação do trabalho pedagógico a partir da educação popular

\begin{tabular}{|c|c|}
\hline Educação popular & Possibilidades \\
\hline $\begin{array}{l}\text { Valorização dos sa- } \\
\text { beres prévios com } \\
\text { a valorização do } \\
\text { saber científico }\end{array}$ & $\begin{array}{l}\text { Previsão de abordagem curricular via PPP na organização e de- } \\
\text { senvolvimento do currículo, formação continuada e avaliação da } \\
\text { aprendizagem. }\end{array}$ \\
\hline $\begin{array}{l}\text { Diálogo, a partici- } \\
\text { pação comunitária } \\
\text { e a formação cida- } \\
\text { dã }\end{array}$ & $\begin{array}{c}\text { Fortalecimento do diálogo com as famílias e a comunidade nas } \\
\text { práticas de gestão, administrativas e pedagógicas, avaliação } \\
\text { institucional com a presença de todos interessados na escola, } \\
\text { gestão democrática pautada na ampliação da participação e } \\
\text { construção coletiva do PPP. }\end{array}$ \\
\hline $\begin{array}{l}\text { Desenvolvimento } \\
\text { do olhar crítico }\end{array}$ & $\begin{array}{l}\text { Formação continuada crítica com os profissionais da educação } \\
\text { da escola, promovendo uma organização curricular que aborde } \\
\text { questões cotidianas que auxiliem na formação política e cidadã } \\
\text { de todos os sujeitos. }\end{array}$ \\
\hline $\begin{array}{l}\text { Valorização do } \\
\text { contexto em que a } \\
\text { escola está inserida }\end{array}$ & $\begin{array}{l}\text { Previsão de conteúdos e abordagens específicas em formação } \\
\text { continuada e a ressignificação constante do PPP com base nas } \\
\text { mudanças contemporâneas do espaço no qual a escola se inse- } \\
\text { re, bem como na abordagem de questões cotidianas no proces- } \\
\text { so de ensino e aprendizagem. }\end{array}$ \\
\hline $\begin{array}{l}\text { Desenvolvimento } \\
\text { da práxis pelo edu- } \\
\text { cador }\end{array}$ & $\begin{array}{c}\text { Formação continuada e proposição constante de reflexão sobre } \\
\text { a prática, com conselhos de classe participativos e reflexivos e } \\
\text { avaliações institucionais que promovam um autoconhecimento } \\
\text { de fato da instituição. }\end{array}$ \\
\hline
\end{tabular}

Fonte: Elaborado pela autora (2020).

Por fim, é preciso afirmar a importância da pedagoga no desenvolvimento das práxis pelo educador, sendo fundamental que ela supere a ideia da or- 
ganização de trabalho fragmentada, pois ela remete à imagem de que existe a separação entre a teoria e a prática, acreditando que cabe à pedagoga propor os conceitos e aos professores efetivar o que já foi estabelecido. Dentro da perspectiva freiriana, é elementar que exista o diálogo entre todos os segmentos. Então, quando se fala da atuação do docente, é preciso ir além de reproduzir um currículo já definido, sendo necessário que ele faça parte do seu processo de construção e reflita sobre suas ações, tornando assim a prática indissociável da teoria, pois uma fundamenta a outra.

\section{CONSIDERAÇÕES FINAIS}

Este trabalho teve como objetivo estabelecer um diálogo sobre possibilidades do embasamento do trabalho da pedagoga na organização do trabaIho pedagógico a partir de alguns pressupostos da educação popular freiriana.

Neste caminho, foram retomados alguns princípios da educação popular em Paulo Freire, um movimento de ideias pautadas na gestão democrática do ensino público que provém, sobretudo, da ideia de educação freiriana. Posteriormente, principalmente com base em Libâneo (2012) e Saviani (2012), retomaram-se algumas características de formação e atuação da pedagoga na organização do trabalho pedagógico para, na sequência, construir um diálogo de possibilidades da atuação dessa profissional com embasamento teórico/ prático da perspectiva freiriana.

No que tange à relação pretendida, evidencia-se que há a possibilidade de se propor um diálogo entre as atribuições da pedagoga na perspectiva freiriana de educação. Partindo da compreensão de que a pedagoga pode ser uma das propulsoras de instrumentos para a transformação social, seu trânsito na construção do PPP, formação continuada, atividades de gestão, administrativas e pedagógicas, condução do processo de avaliação (institucional e da aprendizagem), é necessário ter como base o diálogo, a participação comunitária, a valorização dos saberes prévios e do contexto no qual a escola se insere, o desenvolvimento do olhar crítico e a práxis como um elemento norteador 
constante de seu trabalho e do dos demais profissionais da educação na instituição.

\section{REFERÊNCIAS}

ANTUNES, Ângela; PADILHA, Paulo Roberto. Educação integral, educação cidadã: fundamentos e práticas. São Paulo: Instituto Paulo Freire, 2010.

BRANDÃO, Carlos Rodrigues. Em campo aberto: escritos a sobre educação e a cultura popular. São Paulo: Cortez, 1995.

BRANDÃO, Carlos Rodrigues. Pensar a prática: escritos de viagem e estudos sobre educação. São Paulo: Loyola, 1984.

CANDAU, Vera Maria Ferrão; OLIVEIRA, Luiz Fernandes de. Pedagogia decolonial e educação antirracista e intercultural no Brasil. Belo Horizonte, 2010.

CORDEIRO, Alexander Magno. OLIVEIRA, Gloria Maria. RENTERIA, Juan Miguel. GUIMARÃES, Carlos Alberto. Revisão sistemática: uma revisão narrativa. Rev. Col. Bras. Cir. V. 34, n. 6, p. 428 - 431, nov./dez. 2007.

FREIRE, Paulo. Conscientização: teoria e prática da libertação. São Paulo: Moraes, 1979.

FREIRE, Paulo. Pedagogia da autonomia: saberes necessários a prática educativa. 25 ed. São Paulo: Paz e Terra, 2002.

FREIRE, Paulo. Pedagogia da esperança: um reencontro com a pedagogia do oprimido. Rio de Janeiro: Paz e Terra, 2008.

FREIRE, Paulo. Pedagogia do oprimido. 57 ed. Rio de Janeiro: Paz e Terra, 2014.

FREIRE, Paulo. Educação como prática da liberdade. 28 ed. Rio de Janeiro. Paz e Terra, 2005.

LIBÂNEO, José Carlos. Educação escolar: políticas, estruturas e organização. São Paulo: Cortez, 2012.

SAVIANI, Demerval. O papel do pedagogo como articulador do trabalho pedagógico na sociedade do capital. 2012. 